\title{
AUTISMO E SUPORTE FAMILIAR: RELAÇÕES AFETIVAS ESTABELECIDAS ENTRE CRIANÇAS COM AUTISMO
}

\section{ARTIGO ORIGINAL}

COSTA, Luana Marcia Barros ${ }^{1}$

GONÇALVES, Kariny Guedes Alves Menezes ${ }^{2}$

RODRIGUES, Isabel Cristina Santos ${ }^{3}$

SANTOS, Maria Jessica Pereira Dos ${ }^{4}$

LIMA JUNIOR, Joel ${ }^{5}$

COSTA, Luana Marcia Barros. Et al. Autismo e suporte familiar: Relações afetivas estabelecidas entre crianças com autismo. Revista Científica Multidisciplinar Núcleo do Conhecimento. Ano 05, Ed. 09, Vol. 06, pp. 25-44. Setembro de 2020. ISSN: 2448-0959, Link de

acesso: https://www.nucleodoconhecimento.com.br/psicologia/autismo-e-suporte

\section{RESUMO}

O presente trabalho propõe-se a apontar a importância da família como rede de apoio a crianças com autismo, considerando as relações afetivas como base para o cuidado

${ }^{1}$ Aperfeiçoamento em Formação em mediadores de leitura. Aperfeiçoamento em Violência por parceiro íntimo. Aperfeiçoamento em Formação Em Psicologia Hospitalar. Graduação em andamento em Serviço Social.

2 Especialização em Teorias Psicanalíticas. Especialização em MBA Executivo em Administração. Graduação em Psicologia. Graduação em Administração.

${ }^{3}$ Especialização em andamento em Saúde Coletiva. Graduação em Psicologia.

${ }^{4}$ Graduação em andamento em Psicologia.

${ }^{5}$ Orientador. Mestrado em Ciências da Saúde. Graduação em Psicologia. 
e desenvolvimento destas. O autismo ou Transtorno do Espectro Autista (TEA), é caracterizado como um transtorno global de desenvolvimento e de neurodesenvolvimento, que pode provocar alterações no processo biopsicossocial do sujeito. Por atingir cerca de $1 \%$ da população mundial, o autismo é considerado um assunto de saúde púbica, mostrando a importância de estudos acerca da questão. A Psicologia busca identificar potencialidades e também comprometimentos em relação ao desenvolvimento infantil no espectro autista, promovendo adaptações no contexto familiar e estimulando a criança na busca por sua autonomia. O autismo pode provocar muitos desajustes na rotina familiar, demandando dedicação, afeto e muita resiliência da família, a mesma se torna uma das primeiras e principais redes de apoio durante todo processo maturacional. A metodologia tem um caráter bibliográfico de cunho qualitativo, a coleta de dados foi feita em livro, artigos, periódicos, físicos e online, os descritores foram colhidos a partir do tema e dos objetivos que se propôs trabalhar nesse artigo, classificamos os artigos por temática (autismo, família, afetividade), e por ano de publicação do material, ou seja, sendo a maior parte do material dos últimos cinco anos. Os indivíduos com TEA possuem comprometimento na comunicação, sociabilização e a imaginação. A família se torna os primeiros agentes de socialização e inclusão contribuindo para o desenvolvimento humano. Este suporte familiar está pautado, não somente pelos laços consanguíneos, mas baseada em qualquer organização familiar que esteja alicerçada na afetividade. Essa afetividade esta implicada no desenvolvimento cognitivo, social, e emocional, e, portanto, sendo uma ferramenta importante nas relações da criança com autismo. Apesar do funcionamento familiar ser bastante afetado pelo diagnóstico e pelas mudanças advindas do TEA, é importante que a família possa ressignificar o diagnóstico mobilizando-se em prol do tratamento. Compreende-se que as famílias necessitam de suporte social para enfrentamento do transtorno, se adequando as necessidades e anseios da criança com autismo afim de proporcionar qualidade de vida sendo esse cuidado familiar atravessado pelo afeto.

Palavras Chaves: Autismo, suporte social, família, suporte familiar. 


\section{INTRODUÇÃO}

O Transtorno do Espectro Autista (TEA) caracteriza-se como um transtorno do neurodesenvolvimento que pode acarretar prejuízos ao desenvolvimento global do indivíduo em três principais domínios: interação social, comunicação e comportamento (APA, 2014). Os primeiros sinais e sintomas são geralmente apresentados no decorrer dos primeiros anos de vida, no entanto, os traços característicos do espectro são abrangentes e extensos, variando tanto sob a perspectiva sintomática quanto ao grau de comprometimento em cada pessoa, o que colabora para que a etiologia seja ainda incerta e exposta através de diversas teorias (GROKOSKI, 2016; QUARESMA; SILVA, 2010).

Segundo a Organização das Nações Unidas (ONU) (2016) estima-se que cerca de $1 \%$ da população mundial, ou um em cada 68 indivíduos, sendo a maioria destas crianças, apresenta algum traço do espectro do autista. Além disso, o autismo acomete de maneira geral mais crianças do sexo masculino, não tendo ainda uma comprovação cientifica exata que justifique a maior prevalência em meninos do que em meninas. Apesar de ainda não existirem pesquisas que possibilitem dados precisos quanto a realidade brasileira dentro deste panorama mundial, de acordo com a projeção populacional do Instituto Brasileiro de Geografia e Estatística (IBGE) (2016), estima-se que cerca de 2 milhões de pessoas podem ser incluídas em algum parâmetro clínico do autismo. Devido a essa grande parcela de indivíduos afetados por esta realidade, o assunto apresenta-se como uma questão de saúde pública mundial. Provocando assim, o crescimento ao longo dos anos de pesquisas científicas articuladas em diversas áreas para compreender O TEA e permitir uma maior assistência às crianças com autismo e também a sua família (FADDA; CURY, 2016).

Dentro do conjunto de profissionais que pesquisam, tratam e acompanham estes indivíduos estão médicos, fisioterapeutas, psicólogos, fonoaudiólogos, entre outros. Onde o psicólogo tem atribuições essenciais dentro deste processo, como identificar potencialidades e também comprometimentos em relação ao desenvolvimento infantil, além de auxiliar a criança e seus familiares em questões como a interação social, relações interpessoais e afetivas, comportamentos, entre outros. De maneira a 
promover uma melhor qualidade de vida, visando a autonomia e o progresso da pessoa evitando estereótipos que possam reduzir o sujeito a sua patologia (CAMINHA et al., 2016).

O autismo de várias formas traz desajustes e adversidades ao contexto familiar, provocando a necessidade de adaptação por parte daqueles que zelam e amparam a criança com autismo. Nessa situação o profissional psicólogo torna-se parte fundamental nos processos de fortalecimento de vínculos afetivos e da reorganização da dinâmica familiar. Desta maneira, refletir sobre as práticas e as perspectivas psicológicas no universo autista mostra-se cada vez mais relevante e crescente ao longo dos anos (MONTE; PIO, 2015).

Assim, a inclusão da família como rede de apoio na atenção psicossocial de pessoas com necessidades especiais, incluindo dessa forma também a criança com traços autistas, mostra-se imprescindível dentro das estratégias e dos modelos pautados na reforma psiquiátrica iniciado no Brasil na década de 1970. Sendo, portanto, a família considerada uma conjunção indispensável no auxílio para o estabelecimento das relações sociais e afetivas das crianças com autismo (KOHLRAUSCH; OLSCHOWSKY; SCHNEIDER, 2010; NUNES; AIELLO, 2008).

Sendo assim, apesar das relações afetivas estabelecidas pelas pessoas com TEA mostrarem-se um grande desafio, não só para as mesmas, mas também para família e para a sociedade como um todo, estes vínculos tornam-se colaboradores dentro da superação das dificuldades inerentes ao transtorno (FABRINO, 2012).

De maneira a auxiliar a formação do sujeito a caminho da fase adulta, permitindo que ele desenvolva as suas potencialidades, priorizando as suas necessidades e estimulando sempre sua autonomia. A forma como o indivíduo estrutura-se quanto a aspectos sociais, psicológicos e familiares na infância interfere diretamente nas vivências adultas, e de maneira geral em toda a história do sujeito (NUNES; AIELLO, 2008). Em vista disto, o presente trabalho propõe-se a apontar a importância família como rede de apoio a crianças com autismo, considerando as relações afetivas base para o cuidado e desenvolvimento destas. 


\section{CARACTERIZAÇÃO DO TRANSTORNO DO ESPECTRO AUTISTA (TEA)}

O autismo, ou Transtorno do Espectro Autista (TEA), é caracterizado como um transtorno global de desenvolvimento e de neurodesenvolvimento, que pode provocar alterações no desenvolvimento biopsicossocial do sujeito. É chamado de espectro porque é reconhecido por alguns autores que não existe só um tipo de autismo e sim algumas classificações do mesmo. No que tange o funcionamento autista, esse pode afetar três principais domínios do desenvolvimento: a interação social, a comunicação e o comportamento da criança, ou seja, pode promover um desenvolvimento atípico (BRASIL, 2015; APA, 2014).

A criança pode manifestar comportamento que causem danos a relação de afetividade, ao interesse pelos objetos e por atividades, e não corresponder de forma esperada as atividades socialmente tidas como normais para as fases do desenvolvimento, manifestando comportamentos estereotipados e repetitivos que para a criança são formas de se colocar no ambiente e a responder as demandas externas, é um modo pelo qual a criança projeto para o ambiente o que ela não sabe expressar de outra forma, como também características comportamentais como; agressividade, isolamento, estresse, mal adaptação a lugares estranhos, comportamentos autodestrutivos, desatenção, hiperatividade e impulsividade. autismo acomete mais crianças do sexo masculino do que feminino, e os primeiros sinais pode ser manifestado a partir dos primeiros anos de vida (CAMINHA et al., 2016; DUMAS, 2011).

Conforme a APA (2014) o termo Autismo foi empregado para nomear a perda da capacidade em estabelecer contato com a realidade e dificuldades na comunicação, essas condições têm início precoces e podem comprometer o desenvolvimento do indivíduo. Segundo a classificação do DSM-V um dos principais e mais perceptíveis sinais do autismo é a dificuldade nas relações sócias e afetivas, pontuando que qualquer movimentação externa, ruídos que ameacem romper essa solidão autista é tratada por ele como se não estivessem ali presentes. 
Os prejuízos na interação social podem ser alarmantes, levando o sujeito a não conseguir muitas vezes estabelecer contato visual, expressão facial e gestos corporais. Hans Asperger ressalta em seus estudos sobre o autismo que uma criança com TEA é muito limitada e que a sua personalidade é completamente marcada por essa limitação, demonstrando comportamentos completamente alheios às condições do meio social (MECCA et al, 2010).

Algumas características que servem para auxiliar no diagnostico foram observados por Leo Kanner (1943), colocando que a criança pode ter dificuldade em lidar com mudanças tanto em seu ambiente, como em sua rotina, pelo fato de sua necessidade arraigada em manter a igualdade, a qual somente ele, pode esporadicamente mudar. Kanner, descreve ainda, alguns dos sintomas do Autismo, como a ampla capacidade de memorização de conteúdo sem sentido; possuem também uma hipersensibilidade a estímulos, reagindo de maneira excessiva a muitos ruídos e objetos, além de apresentarem problemas com a alimentação. Asperger (ou autismo tipo 1 ou leve) pontua que mostrar-se obcecado e compulsivo nos pensamentos é característico de uma pessoa que possui transtorno do espectro autista (BELIZÁRIO FILHO; CUNHA, 2010).

Segundo o DSM-V (APA, 2014) o autismo clássico, que se caracteriza por problemas na comunicação, interações sociais e a emissão de comportamentos repetitivos, geralmente diagnosticado antes dos três anos de idade, pode variar entre leve ou alto funcionamento a de grave ou baixo funcionamento. $O$ de alto funcionamento compromete aspectos como a linguagem em atraso ou não desenvolvimento desta, causando assim, uma dificuldade na interação social. $O$ autismo de baixo funcionamento é um dos casos mais graves, pois seus sintomas são profundos, envolvendo déficits de habilidades de comunicação, habilidades sociais fragilizadas e movimentos repetitivos estereotipados.

Os sinais e sintomas do TEA podem ser exteriorizados de maneiras diferentes, podendo ser mais leves em uns e mais grotescos em outros e suas primeiras manifestações podem ser notadas por seus cuidadores antes dos 36 meses de vida da criança. Dentre os sintomas observados pelos pais, o retardamento no 
desenvolvimento da comunicação e da linguagem são os expostos com maior frequência. Porém, alguns estudos apontam que dificuldades com o relacionamento social são expressos primariamente (ZANON; BACKES; BOSA, 2014)

Em geral os indivíduos portadores TEA possuem comprometimento nas três áreas do desenvolvimento humano a comunicação, a sociabilização e a imaginação, portanto quanto mais cedo os sinais e sintomas são identificados mais cedo o tratamento deverá ser iniciado (CAMINHA et al., 2016).

Os principais critérios do diagnóstico de TEA no DSM-V: O indivíduo possui déficit na comunicação verbal e não verbal, na interação social, dificuldade de manter e desenvolver relacionamentos, como também nas relações sócio emocionais, possui padrões de comportamentos repetitivos e restritos podendo também apresentar comportamentos estereotipados ter fixação nas rotinas, falta de aceitação das mudanças, interesse fixo, restrito e intensidade de foco, hiper ou hipo reatividade para percepção sensorial de estímulos ao ambiente, dificuldade com a imaginação, os sintomas costumam estar presente na primeira infância, o conjunto dos sintomas limitam ou impossibilitam o funcionamento diário do indivíduo (APA, 2014).

O diagnóstico de TEA também depende de alguns fatores:

- Entender a criança autista e seus sinais e sintomas de forma aprofundada;

- A observação do comportamento da criança em casa, na escola, com a família no contexto social é importante;

- Verificar fotos e vídeos dessa criança em ambientes sociais como festa de aniversário;

- Solicitar relatórios da escola com informações detalhadas sobre a criança;

- Manter os pais informados do diagnóstico e da importância do tratamento (APA, 2014) (CAMINHA et al., 2016).

A variabilidade dos sintomas que podem se apresentar de maneira súbita, lentamente progressiva e regressiva e isso dificulta muitas vezes o diagnóstico que pode estar associado a fatores neuropatológicos como também outras condições 
neuropsiquiátricas como epilepsia, fobia social, deficiência intelectual, hiperatividade entre outros. Por tanto é de suma importância a avalição de uma equipe interdisciplinar que possibilite um rápido direcionamento e uma terapêutica adequada a cada indivíduo (CAMINHA et al., 2016).

A comunicação do diagnóstico para os familiares pode ser algo devastador, pois diante do nascimento de uma criança que é idealizada pelos pais e por toda família, quando ocorre uma ruptura nesses planos esse momento do diagnóstico é permeado de diversos sentimentos como culpa, desespero, negação, insegurança, medo, tristeza, desesperança, luto , diante disso é necessário que haja uma aproximação dos profissionais envolvidos e a família de forma que a comunicação possa ser feita de maneira calma, clara, honesta, respeitosa compreensiva considerando os fatores sócio culturais da família objetivando gerar menos tensão e conflitos por parte dos familiares (PINTO et al., 2016).

\section{INCLUSÃO, SOCIALIZAÇÃO E APRENDIZAGEM DA CRIANÇA COM AUTISMO, E A INFLUÊNCIA DO AFETO EM AMBOS PROCESSOS}

A inclusão, socialização e aprendizagem da criança com autismo começa no ambiente familiar. A família exerce o papel de educadora, ela lança a criança no meio social, é ela que se empodera das leis, diretrizes, cartilhas para ajudar o filho, ou o parente a ter o direito de ser incluído em diversos ambientes sociais e educacionais, como a escola (MATSUMOTO; MACÊDO, 2012).

A inclusão da criança com autismo na escola, ainda hoje, tem seus desafios, apesar da implementação de leis que amparam os pais de seus direitos quanto a oferta de escolas inclusivas, ainda se encontra muita resistência quanto inclusão efetiva da criança no ambiente escolar. Os pais, diante desse impasse passam grande parte do seu tempo transmitindo e ensinando a criança no ambiente domiciliar. Os primeiros contatos socializadores, geralmente são com os familiares mais próximos, são com brinquedos interativos, uso das tecnologias, e de algumas técnicas terapêuticas ensinadas pelos psicólogos ou outros profissionais que acompanhem a criança (LEMOS; SALOMÃO; AGRIPINO-RAMOS, 2014; SERRA, 2012). 
A aprendizagem do sujeito com autismo, que possui dificuldades na comunicação e no domínio da linguagem, necessita de uma atenção aos limites do indivíduo para que as práticas pedagógicas possam ser aplicadas, mas sempre incentivando o sujeito a superar seus limites. A inclusão desses alunos no ensino regular é importante para seu desenvolvimento social, porém, essa inclusão gera vários desafios pois não é só inserir esses indivíduos em um contexto escolar, mais é necessário considerar suas peculiaridades (NASCIMENTO; CRUZ, 2014).

A criança com autismo é capaz de aprender como outra criança, porém as técnicas e as intervenções deverão ser utilizadas para facilitar esse processo considerando a individualidade de cada criança, levando em conta suas preferencias e ritmo de aprendizagem e seu modo de estar no mundo, os educadores junto com os pais são essenciais nesse processo de aprendizagem. A capacitação dos profissionais é bastante importante pois os mesmos podem sentir dificuldade de interagir com as crianças e isso dificulta o processo de inclusão das mesmas (COSTA, 2016; MATSUMOTO; MACÊDO, 2012).

A Lei no 12.764 veio garantir direitos aos indivíduos com TEA, como promover ações e serviços de saúde, como serviços nutricionais, medicamentos, equipe multidisciplinar entre outros, prevê também que alunos com TEA sejam inseridos na rede de ensino regular e quando esses comprovem a necessidade terão direito a um acompanhante que será financiado pelo governo (BRASIL, 2012).

Um fator importante é limitação do número de alunos na sala de aula para que o professor possa prestar uma assistência satisfatória a esses alunos. Esses alunos apesar de possuírem dificuldade na linguagem, porem na maioria das vezes são dotados de uma boa percepção visual que o educador pode utilizar para trabalhar, ao invés de estímulos verbais utilizar estímulos visuais. Por tanto havendo interesse do aluno pode ser explorado desenhos e atividades em computador pois estão ligadas a percepção visual. A sensibilidade sonora também é um ponto a ser trabalhado pois o barulho é bastante incômodo para eles, mas cantar pode ser utilizado como um estímulo de aprendizagem (REIS; PEREIRA; ALMEIDA, 2016; NASCIMENTO; CRUZ, 2014). 
O trabalho com crianças com TEA deve ser feito com afeto e paciência, buscando sempre conhecer as especificidades de cada sujeito e potencializar suas habilidades levando sempre em consideração que essas crianças possuem sensações que devem ser acolhidas e respeitadas. Diante disso, a inclusão com respeito e afeto possibilitara melhorias na vida do indivíduo com TEA promovendo sua melhor interação social, cognição e melhorando assim o comportamento, como também para suas habilidades e competências sociais o seu desenvolvimento de modo geral (COSTA, 2016; REIS; PEREIRA; ALMEIDA, 2016).

A inclusão e a aprendizagem são produtos da socialização dessa criança, e parte da capacidade mesmo que minimamente da criança de interagir no meio social, através dessa interação ela vai conseguir se sentir mais incluída aprendendo do seu modo, e a depender de suas necessidades realizar atividades importantes no dia a dia, dessa forma novas redes de apoio vão se formando, por exemplo, novos vínculos de amizade tanto para criança como para os pais. A família tem esse papel inicial, primário, importantíssimo, a inclusão da criança com autismo começa em casa, os pais promovem inclusão, socialização no ambiente domiciliar, eles são os primeiros agentes de inclusão dessa criança, essa relação de interesse, de empoderamento sobre as limitações do filho, tonam essa relação mais real, real no sentido de compreender até onde pode ir, e até onde é benéfico para criança progredir, e esse relação deve ser permeada de afetos (SOUZA, 2016; SOUSA, 2014; ANDRADE; TEODORO, 2012).

\section{SUPORTE FAMILIAR COMO FERRAMENTA AFETIVA PARA O DESENVOLVIMENTO DA CRIANÇA COM AUTISMOS}

Através de autores como Wallon (2010), a aprendizagem e o desenvolvimento infantil mostram-se diretamente relacionados a aspectos afetivos manifestados dentro destes processos. Segundo o autor, a interação com o meio social é fundamental não apenas quanto ao progresso educacional, mas também quanto à perspectiva de construção pessoal. De acordo ainda com Piaget (1986) a afetividade encontra-se conectada ao 
avanço infantil, ao se considerar as emoções e sentimentos como fatores motivacionais das operações cognitivas.

Concomitante a estes princípios, a teoria da mente, desenvolvida por Cohen et al., (1985, apud GUERRER; MENEZES, 2014), sugere que em torno dos quatro anos de idade o indivíduo começa a desenvolver a capacidade de perceber os comportamentos do outro através de estados mentais (crenças, desejos, conhecimentos), que são particulares e diferentes para cada um. Assim sendo, crianças com o transtorno do espectro autista dentro desta concepção mental, sofrem dificuldades em expressar emoções, compreender as emoções dos outros e a empatia. Consequentemente interferindo na comunicação e interação inerente ao cotidiano familiar e social.

Considerando o desenvolvimento da criança nesta estreita relação com o ambiente, a base para a construção de aspectos individuais, como a personalidade, encontra-se grande parte nas relações familiares. A forma como o sujeito adequa-se ao meio social e escolar, ou seja, suas ações e suas condutas nestes espaços relacionam-se diretamente com a sua dinâmica familiar (SOUZA; BARBOSA, 2016; MATOS et al., 2012).

A família representa um espaço de socialização e torna-se, portanto, local de relevante importância para a compreensão do desenvolvimento humano, onde alguns sujeitos irão expressar seus primeiros comportamentos, é também local de exercício de cidadania, e de crescimento individual ou do grupo. Cada família possui sua própria dinâmica, trazendo consigo suas cresças, valores que estarão caracterizados tanto por fatores da própria subjetividade do sujeito, como por fatores externos aos quais estão inseridos (FACO; MELCHIORI, 2009).

Inúmeras mudanças ocorreram ao longo da história da humanidade no que se compreende quanto família e deu origem a novas concepções, que não são mais equiparadas à família tradicional patriarcal. No entanto, foi somente quando entrou em vigor a Constituição Federal de 1988, onde se instaurou a igualdade entre homem e mulher que o conceito de família foi ampliado. A família atual, além da 
consanguinidade, está pautada na afetividade, nas relações de liberdade e responsabilidades construídas através dos vínculos estabelecidos com pessoas de seu convívio. Este afeto que se apresenta de maneira espontânea, com significado de amizade, de reciprocidade entre sujeitos tem se tornado a principal motivação para se estabelecer ligação entre os seres humanos (MARIANO, 2009).

Portanto, assim como sugere Matos et al, (2012), dentro da perspectiva de um indivíduo com necessidades especiais, assim como é o caso do autismo, é necessário compreender o sujeito nos seus progressos maturacional, para a partir disso perceber as necessidades de cada indivíduo particularmente. Dando prioridade desse modo, a visão do ser humano enquanto pessoa única e singular, e posterior a isso ao transtorno existente.

Quando a família recebe o diagnóstico de autismo, é como se os pais sofressem um processo de luto, luto pelo filho idealizado, pelos sonhos e pelas perspectivas nutridas até então para essa criança, a princípio há sentimentos ambivalentes como negação, culpa, tristeza, amor, ódio, aceitação, rejeição, e ao mesmo tempo acontece uma ressignificação e um gerenciamento de afetos, pois os pais e familiares compreendem que precisam acolher e conhecer o autismo ou qualquer outro tipo de deficiência do filho real que se apresenta, nesse momento morre o filho idealizado e nasce o filho real, com uma deficiência que pode vir a lhe causar desvantagens, incapacidades e limitações ao longo de seu desenvolvimento, e essas atribuições da deficiência não podem paralisar os pais e sim mobiliza-los (SILVA, 2006; AMARAL, 1995).

Alguns aspectos influenciam o modo pelo qual a família vai ressignificar o diagnóstico e enfrentar a deficiência como algo a ser primeiro conhecido e adaptado, esses aspectos são o modo como essa família recebeu esse diagnóstico e os sentimentos que ficaram marcados nesse momento; as informações pertinentes e necessárias que os mesmos receberam sobre a doença; as redes de apoio disponíveis para que essa família para que possa enfrentar os momentos de crise; nível socioeconômico; a estrutura emocional dessa família e seu histórico anterior; o nível de comprometimento físico, intelectual, psicossocial e motor dessa criança; e suas expectativas em relação ao futuro de seu filho com autismo e das redes de apoio que ele precisara durante 
toda sua vida, esses fatores angustiam os pais e os fazem pensar o que será do filho quando eles já não existirem mais? Quem vai cuidar e se dedicar ao filho? São perguntas que estão a todo momento nos pensamentos, nos diálogos em grupos de apoio e em todos os momentos em que se trata do futuro dessa criança (SOUZA, 2016; SOUSA, 2014).

O impacto causado pelo autismo vai mobilizar toda a interação familiar e a forma como essa se organiza, pois a rotina dos pais, a interação social dos pais, as amizades e lugares frequentados, vão sofrer mudanças, como também as perspectivas de futuro dessa família, a criança com autismo impacta a família em todos os aspectos, sociais, ambientais, emocionais, financeiros, conjugais, é um amontoado de mudanças que serão internalizadas pelos pais, mudanças essas que não são fáceis pois são permeadas de dúvidas, de enfrentamento dos sintomas, de culpa, de frustrações, de medo, vergonha, e até isolamento social por receio que o filho com autismo que já tem características antissociais sofra com rejeição, e falta de empatia por parte de outros pais e de outras crianças (CUSTÓDIO, 2014; MAIA FILHO et al., 2016).

Os pais, irmãos, e familiares próximos, em sua grande maioria não estão preparados para se adaptar as mudanças, mas o que move essas pessoas é o afeto pela criança. O diagnóstico é um detalhe que norteia o melhor tratamento e o cuidado a ser ofertado a essa criança por conta das vulnerabilidades proporcionadas pelo autismo, mas, o que realmente diferencia esse cuidado é a capacidade afetiva das pessoas que estão ao redor da criança. $\mathrm{O}$ autista apresenta dificuldades de se relacionar afetivamente, a criança não responde as manifestações de afeto dos pais e dos familiares como os mesmos gostariam, ou como socialmente é aprendido, por exemplo, corresponder a um abraço. O fato da criança responder ou não responder ao afeto, ou até mesmo responder da sua forma sem que essa manifestação seja compreendida por quem é afetuoso não quer dizer que a criança não precise, ou melhor, não necessite de afeto para se desenvolver como qualquer outra criança sem autismo (OLIVEIRA et al., 2014).

É necessário ficar claro que não é porque uma tal característica é comum a criança com autismo, por exemplo, comportamentos estereotipados de passar horas girando 
em torno de si mesmo, que o responsável deixara que o mesmo passe ali uma hora girando em torno de si, com o pretexto de que esse comportamento é natural a criança com autismo. Essa situação faz alusão ao afeto, não é porque a criança não é afetuosa, não compreende o afeto, ou até mesmo afetividade pode ser invasiva para essa criança que a mesma não precisara receber afeto e apoio de sua família (ZANATTA et al., 2014).

A criança com autismo se desenvolve, apesar de suas limitações próprias da deficiência. Ter contato com afetos sejam eles de alegria, tristeza, raiva, carinho, amor, atingem a criança de uma forma individual e subjetiva, que só ela em sua singularidade pode sentir. Os reflexos de ter pais que a pesar de toda dor e ressignificação vivenciadas tem a resiliência de amar o filho real, o filho que existe, modifica a forma de tratar e educar essas crianças, o que acaba por implicar no modo pelo qual as pessoas ao redor enxergam o autismo (BRAZÂO, 2015; SOUSA, 2014).

Os pais entendedores dos sinais sintomas, das manifestações possíveis e comuns ao autismo, conseguem verdadeiramente ajudar seus filhos. Construir uma relação onde os pais conseguem acessar e se conectar com o mundo do filho é essencial, afinal de contas o maior contato social nos primeiros anos de vida ao qual a criança autista vai ter acesso são seus pais e irmãos, eles vão ser para essa criança uma rede de apoio, onde o mesmo se ampara e encontra segurança, são essas pessoas que ajudaram a criança na elaboração de quem ela é, de sua autoestima e autonomia. A forma como os pais reagem as manifestações do autismo ajudaram a criança a gerenciar seus próprios sentimentos e afetos, orientando-a a lidar com essa mesma situação em outros lugares ou momentos (SOUZA; BARBOSA, 2016).

A afetividade implica na forma como esse sujeito vai se desenvolver em todos os aspectos, físicos, cognitivo, sociais, psicossociais, é a forma pela qual a criança com autismo pode encontrar possibilidades de criar vínculos aumentando sua rede de apoio, é necessário estimular a criança a vivenciar suas próprias experiências subjetivas e não as limitar a um diagnóstico ou a um sintoma (MATOS et al., 2012). 
A família como rede de apoio sempre vai estar presente na vida da criança com autismo, em todas as etapas de seu desenvolver, a maior parte do aprendizado, das formas de inclusão, da socialização, e dos afetos que essa criança vai construir em seu desenvolvimento serão oriundos de sua relação familiar. A família ser torna uma rede de apoio à medida que a mesma está bem orientada sobre o que é autismo, sobre as condições reais do desenvolvimento de seu filho, e sobre os desafios que vão ser enfrentados a medida de cada fase de crescimento da criança, essas concepções serão melhor internalizadas com as redes de apoio que a família terá, como; médicos, terapeutas ocupacionais, psicólogos, fonoaudiólogos, psicopedagogos, professores, grupos de mães, grupos de apoio para pais, leis que ajudem e viabilizem os direitos da pessoa com autismo, entre outras redes sociais de apoio. Todas essas redes e algumas mais ajudaram os pais que consequentemente serão as redes de apoio de seus filhos com autismo (SOUZA; BARBOSA, 2016; OLIVEIRA et al., 2014).

\section{METODOLOGIA}

O presente trabalho é caracterizado por um estudo bibliográfico de caráter teórico qualitativo, que significa dizer que a pesquisa está amparada por livros, artigos científicos, periódicos, monografias, dissertações de mestrado e doutorado, oriundo de pesquisas qualitativas. É feito um estudo geral nas plataformas de disponibilização online e nos livros sobre a temática, como também uma análise criteriosa da fidedignidade e confiabilidades dos dados já publicados e sua atualização no período (PRODANOV; FREITAS, 2013; FLICK, 2009; LAKATOS; MARCONI, 2010).

A coleta de dados foi feita no período de três meses, de março a maio de 2017, nesse período começamos a pesquisar sobre a temática e a coletar os materiais necessários, essa coleta foi feita em sites de revistas cientificas/periódicos online como também em cartilhas e livros físicos e online sobre temática que se propôs estudar. Essas plataformas e sites foram: Google acadêmico, plataforma Scielo, revistas eletrônicas como: psicologia em foco; Revista Psico Puc Rs; Revista Gaúcha de Enfermagem; academia paulista de psicologia; Revista de Psicologia da Criança e do Adolescente, Lisboa; Revista elo-diálogos em extensão; Psicopedagogia; Revista 
Brasileira de Educação Especial; Revista Medica Estilos Clínicos. Como também o banco de dados de monografias e dissertações de mestrado e doutorado de algumas universidades como Universidade Federal de São Carlos, Universidade Algarve, e Universidade de Santa Catarina. Foram usados livros físicos e eletrônicos, como também cartilhas e leis do ministério da saúde.

O critério de seleção usado para classificar os artigos e capítulos que seriam usados foi captar aqueles que melhor conseguiriam contemplar a temática, e nos ajudar a articular o tema geral com o tema específico ao qual nos propomos a trabalhar nesse artigo. Classificamos os artigos por temática (autismo, família, afetividade), e por ano de divulgação e publicação do material, ou seja, sendo a maior parte do material dos últimos cinco anos. Com essa classificação procurou-se por conteúdos que conseguissem traspassar de forma clara o conceito de autismo, sinais e sintomas, como o diagnóstico pode ser feito, as necessidades de socialização e inclusão dessa criança no meio social, educacional, a capacidade de socialização da criança autista e comtemplando todos esses conteúdo com o tema principal referente a influência da família para o desenvolvimento autista e a relação entre afetividade e família como rede de apoio para o desenvolvimento da mesma.

Os descritores escolhidos foram; Autismo; Família; Afetividade; esses definem o que o trabalho se propõe a explanar, e dá ao leitor um resumo claro do que se trata o trabalho e os tópicos que ali serão abordados. Essas palavras foram essenciais para que pudéssemos ter êxito nas pesquisas, e para que pudéssemos deixar explícito para o leitor do que o trabalho se propõe a discutir.

\section{CONSIDERAÇÃO FINAIS}

Percebe-se diante da realidade enfrentada que as famílias irão sofrer mudanças na sua rotina, serão afetadas por uma sobrecarga de tarefas, por exigências especiais que a criança irá demandar. É necessário que as mesmas se unam para que juntas possibilitem a formação de uma rede de apoio para esse indivíduo. Essas famílias necessitam de amparo profissional para que possam elaborar os sentimentos e que 
busquem juntos estratégias de enfrentamento, ajustamento e ressignificação da realidade do filho.

Desta maneira relatamos que a orientação dessas famílias é de muita importância pois ajuda a diminuir a dor e a angústia de encarar a perca do filho idealizado, passando a conviver com essa nova realidade, colaborando para uma relação familiar mais tranquila. A inclusão deve iniciar tanto no ambiente familiar como no ambiente escolar pois são nesses espaços que o sujeito irá se desenvolver, portanto o indivíduo deverá ser acolhido e aceito respeitando suas individualidades. A afetividade terá grande importância nesse processo pois é através dela que poderá tornar o ambiente estimulante para o aprendizado, instigando assim a troca de saberes entre família e criança, como também professor e aluno.

Contudo convém observar que estimular o afeto da criança com TEA possibilita conhecer melhor esse sujeito, entender como ele se coloca no mundo, seus interesses, sonhos, habilidades e dificuldades procurando assim desenvolver sua sociabilidade e comunicação. Devemos, portanto, enfatizar a importância do apoio que a família tem que receber de forma que ela se sinta acolhida e que junto aos profissionais possa buscar caminhos que levem a estimular o aprendizado e o desenvolvimento dessa criança.

Podemos constatar então que diante dos aspectos apresentados, para que haja uma melhor evolução e educação para indivíduos com TEA é preciso que haja uma integração da família, sociedade e escola. Pretendemos contribuir através desse trabalho, para que se possa aumentar a percepção acadêmica e social da importância do cuidado afetuoso a criança com autismo e o aumento das redes de apoio necessárias para o desenvolvimento da mesma. Conscientizando da importância do afeto na constituição familiar e no desenvolvimento das relações com a criança que tem TEA. 


\section{REFERÊNCIAS}

AMARAL, L. A. Conhecendo a deficiência (em companhia de Hercules). São Paulo: rede editorial, 1995.

AMERICAN PSYCHIATRIC ASSOCIATION -APA- (2014). Manual Diagnostico e Estatístico de Transtornos Mentais-DSM-V - (5 eds. Ver). - Porto Alegre: Editora Artmed.

ANDRADE, A. A. E ;TEODORO, M. L. M. Família e Autismo: Uma Revisão da Literatura. Contextos Clínicos, 5(2)133-142, julho-dezembro 2012. Disponível em: <http://pepsic.bvsalud.org/pdf/cclin/v5n2/v5n2a08.pdf>. Acesso em: 20 Mai. 2016.

BELISÁRIO FILHO, J. F; CUNHA, P. Educação especial na perspectiva da inclusão escolar, transtornos globais do desenvolvimento. V. 9, 2010. 44p. Disponível em: <https://central3.to.gov.br/arquivo/299634/>. Acesso em: 01 Jun. 2017.

BRAZAO, J. C. C. A Implicação do Afeto na Psicologia do Desenvolvimento: uma Perspectiva Contemporânea. Psicol. cienc. prof., Brasília , v. 35, n. 2, p. 342358, Junho, 2015 Disponível em: $<$ http://www.scielo.br/scielo.php?script=sci_arttext\&pid=S141498932015000200342\&lng=pt_BR\&nrm=iso >. Acesso em: 30 Ago. 2017.

BRASIL, Lei no 12.764 de 27 de dezembro de 2012. Política Nacional de Proteção dos Direitos da Pessoa com Transtornos do Espectro Autista. Presidência da República, Casa Civil. Disponível em: <http://www.planalto.gov.br/ccivil_03/_ato20112014/2012/lei/l12764.htm>. Acesso em: 20 Abr. 2017.

BRASIL. Ministério da Saúde. Secretaria de Atenção à Saúde. Departamento de Atenção Especializada e Temática. Linha de cuidado para a atenção às pessoas com transtornos do espectro do autismo e suas famílias na Rede de Atenção Psicossocial do Sistema Único de Saúde / Ministério da Saúde, Secretaria de Atenção à Saúde, Departamento de Atenção Especializada e Temática. - Brasília: Ministério da Saúde, 2015. 156 p.: il. Disponível em: 
$<$ http://bvsms.saude.gov.br/bvs/publicacoes/linha_cuidado_atencao_pessoas_transt orno.pdf >. Acesso em: 15 Mar. 2017.

CAMINHA, V; HUGUENIN, J; ASSIS, L; ALVES, P. Autismo: vivências e caminhos. São Paulo, 2016. p.46-51. Disponível em: <http://pdf.blucher.com.br.s3-sa-east1.amazonaws.com/openaccess/9788580391329/completo.pdf>. Acesso em: 21 Abr. 2017.

COSTA, D. Processo de Aprendizagem da Criança com Autismo na Escola Regular. Universidade Federal da Bahia, 2016. Disponível em:<https://repositorio.ufba.br/ri/bitstream/ri/19898/1/VERS\%c3\%830\%20FINAL.pdf >. Acesso em: 22 Abr. 2017.

CUSTÓDIO, C. S. Autismo: diminuição do impacto junto a família. Monografia apresentada ao Curso de Especialização em Linhas de Cuidado em Enfermagem Atenção Psicossocial do Departamento de Enfermagem da Universidade Federal de Santa Catarina-UFSC. Florianópolis, 2014. Disponível em:< https://repositorio.ufsc.br/bitstream/handle/123456789/167229/Claudia\%20de\%20So uza\%20Custodio\%20-\%20Psico\%20-\%20TCC. pdf?sequence=1\&isAllowed=y:>. Acesso em: 23 Mar. 2017.

DUMAS, J. E. Psicopatologia da infância e da adolescência. 3. ed. Porto Alegre: Artmed, 2011.640p.

FABRINO, N. V. Afetividade e base familiar: norteadores da formação da personalidade. UNISAM/ Faculdade Norte Capixaba de São Mateus, São Mateus, 2012. Disponível em: <http://saomateus.multivix.edu.br/wpcontent/uploads/2013/05/Afetividade-e-base-familiar_norteadores-da-formacao-dapersonalidade.pdf>. Acesso em: 28 Abr. 2017.

FACO, V. M. G.; MELCHIORI, L. E.; Conceito de família: adolescentes de zona rural e urbana. São Paulo, 2009. Disponível em: <http://books.scielo.org/id/krj5p/pdf/valle9788598605999-07.pdf>. Acesso em: 30 Abr. 2017. 
FADDA, G. M; CURY, V. E. O enigma do autismo: contribuições sobre a etiologia do transtorno. Psicologia em estudo, Maringá, v. 21, n. 3, p. 411-423, jul./set. 2016. Disponível em: <http://www.redalyc.org/pdf/2871/287148579006_2.pdf>. Acesso em: 07 Mai. 2017.

FLICK, U. Introdução à Pesquisa Qualitativa-3. Artmed Editora, 2009.

GUERRER, B. L; MENEZES, J. L. Percepção musical em crianças autistas: melhora de funções interpessoais. Ciência \& cognição, s.l, fev. 2014. Disponível em: $<$ http://cienciasecognicao.org/neuroemdebate/?p=1393>. Acesso em: 28 Abr. 2017.

GROKOSKI, K. C. Composição corporal e avaliação do consumo e do comportamento alimentar em pacientes do transtorno do espectro autista. Universidade Federal do Rio Grande do Sul, Porto Alegre, 2016. Disponível em: $<$ https://www.lume.ufrgs.br/bitstream/handle/10183/149591/001006586.pdf?sequenc e=1>. Acesso em: 04 Abr. 2017.

IBGE - Instituto Brasileiro de Geografia e Estatística. Projeção da população do Brasil e das Unidades da Federação. 2016. Disponível em: http://www.ibge.gov.br/apps/populacao/projecao/. Acesso em: 06 Mai. 2017.

KOHLRAUSCH, E; MIELKE, F.B; OLSCHOWSKY, A; SCHNEIDER, J.F. A inclusão da família na atenção psicossocial: uma reflexão. Rev. Eletr. Enf. [Internet]. 2010 out/dez;12(4):761-5. Disponível em: <http://dx.doi.org/10.5216/ree.v12i4.6812>. Acesso em: 14 mai. 2017.

LEMOS, E. L. M. D; SALOMAO, N. M. R; AGRIPINO-RAMOS, C. S. Inclusão de crianças autistas: um estudo sobre interações sociais no contexto escolar. Rev. bras. educ. espec., Marília , v. 20, n. 1, p. 117-130, Mar. 2014 . Disponível em: $<$ http://www.scielo.br/scielo.php?script=sci_arttext\&pid=S141365382014000100009\&Ing=en\&nrm=iso >. Acesso em: 30 Ago. 2017. 
MAIA FILHO; A. L. M. A importância da família no cuidado da criança autista. Revista saúde em foco. Teresina, v.3, n.1, art, 1p. 03-24, jan/julho. 2016. Disponível em: <www4.fsanet.com.br/revista>. Acesso em: 06 Mai. 2017.

MARIANO, A. B. P. As mudanças no modelo tradicional familiar e o afeto como pilar de sustentação destas novas entidades familiares. 2009. Disponível em: $<$ http://www.unibrasil.com.br/arquivos/direito/20092/ana-beatriz-paranamariano.pdf>. Acesso em: 16 Mai. 2017.

MARCONI, M. A; LAKATOS, E. M. Fundamentos de metodologia científica. 7. ed. São Paulo: Atlas, 2010.

MATOS, M.A. S.; BRAGA, G. V.; STELLI, M. N. M.; CHAVES, N. S; SILVA, R. M. M.; VINENTE, S. A contribuição de Wallon para o desenvolvimento e aprendizagem da criança autista. Elo: Diálogos em Extensão. Universidade Federal de Viçosa, v. 1, p. 19-38, 2012. Disponível em:< http://www.elo.ufv.br/index.php/elo/article/view/2>. Acesso em: 28 Abr. 2017.

MATSUMOTO, A. S ; MACÊDO, A. R. R. A Importância da família no processo de inclusão. Interfaces da Educ., Paranaíba, v.3, n.9, p.5-15, 2012. ISSN2177-769. Disponível em: $<$ http://periodicosonline.uems.br/index.php/interfaces/article/view/546> Acesso em: 20 Mai. 2017.

MECCA, P. T.; BRAVO, R. B.; VELLOSO, R. L.; SCHWARTZMAN, J. S.; BRUNONI, D.; TEIXEIRA, M. C. T. V. Rastreamento de sinais e sintomas de transtornos do espectro do autismo em irmãos. Rio Grande do Sul, 2010. Disponível em: <http://www.scielo.br/pdf/rprs/v33n2/v33n2a09>. Acesso em: 30 Abr. 2017.

MONTE, L. C. P; PINTO, A. A. Família e Autismo: Psicodinâmica Familiar diante do Transtorno e Desenvolvimento Global na Infância. Revista Estação Científica. Juiz de Fora, n. 14, jul - dez, 2015. Disponível em: $<$ http://portal.estacio.br/docs\%5Crevista_estacao_cientifica/02-14.pdf >. Acesso em: 07 Abr. 2017. 
NASCIMENTO, F, CRUZ, M. Da Realidade à Inclusão: uma investigação acerca da aprendizagem e do desenvolvimento do/a aluno/a com Transtorno do Espectro Autista- TEA nas series iniciais do I segmento do Ensino Fundamental. Rev. Polyphonia, Rio de Janeiro, 2014. Disponível em: $<$ https://www.revistas.ufg.br/sv/article/viewFile/38149/19306>. Acesso em: 22 Abr. 2017.

NUNES, C. C; AIELLO, A. L. R. Interação entre irmãos: deficiência mental, idade e apoio social da família. Psicol. Reflexo. Crit. , Porto Alegre, v. 21, n. 1, p. 42-50, 2008. Disponível em: <http://www.scielo.br/scielo.php?pid=S010279722008000100006\&script=sci_abstract\&tlng=pt>. Acesso em: 14 Mai. 2017.

OLIVEIRA, D; MOURA, A; FEIJÓ, L PINHEIRO, M; BRITES, P; DORNELES, S, MOURA, E. Interação Vincular de Pais com Filhos Autistas. Revista de Psicologia da criança e do adolescente. 2014. Disponível em: <http://revistas.lis.ulusiada.pt/index.php/cipca/article/view/659>. Acesso em: 23 Abr. 2017.

ONUBR. Organização das Nações Unidas no Brasil. Disponível em: $<$ https://nacoesunidas.org/rejeitar-pessoas-com-autismo-e-um-desperdicio-depotencial-humano-destacam-representantes-da-onu/>. Acesso em: 04 Abr. 2017.

PIAGET, J. A Linguagem e o pensamento da criança. Trad. Manuel Campos. São Paulo: Martins Fontes, 1986. 212p.

PINTO, R; TORQUATO, I; COlLet, N; REICHERT, A; NETO, V; SARAIVA, A. Autismo infantil: Impacto do diagnóstico e repercussões nas relações familiares. Revista Gaúcha de Enfermagem, 2016. Disponível em: <http://www.scielo.br/pdf/rgenf/v37n3/0102-6933-rgenf-1983144720160361572.pdf>. Acesso em: 23 Abr. 2017.

PRODANOV, Cleber Cristiano; FREITAS, Ernani Cesar De. Metodologia do trabalho científico [recurso eletrônico]: métodos e técnicas da pesquisa e do trabalho acadêmico. - 2. ed. - Novo Hamburgo: Feevale, 2013. Disponível em: 
<http://www.feevale.br/Comum/midias/8807f05a-14d0-4d5b-b1ad-1538f3aef538/Ebook\%20Metodologia\%20do\%20Trabalho\%20Cientifico.pdf>. Acesso em: Mar. 2017.

QUARESMA, H. D. V; SILVA, V. G. Autismo Infantil: Concepções e Práticas Psicológicas. Revista Brasileira de Ciências da Saúde, v. 14, n.4, 2010. Disponível em: <http://periodicos.ufpb.br/ojs2/index.php/rbcs>. Acesso em: 06 Mai. 2017.

REIS, Helena Isabel da Silva; PEREIRA, Ana Paula da Silva; ALMEIDA, Leandro da Silva. Características e Especificidades da Comunicação Social na Perturbação do Espectro do Autismo. Rev. bras. educ. espec., Marília , v. 22, n. 3, p. 325336 , Set. 2016

Disponível em: http://www.scielo.br/scielo.php?script=sci_arttext\&pid=S141365382016000300325\&lng=en\&nrm=iso>. Acesso em: 25 Mai. 2017.

SERRA, Dayse. AUTISMO, FAMÍlIA E INCLUSÃO. POLÊMICA. 9, mar. 2012. Disponível em: $<$ http://www.epublicacoes.uerj.br/index.php/polemica/article/view/2693>. Acesso em: 24 Mai. 2017.

SILVA, Luciene M. Da. O estranhamento causado pela deficiência: preconceito e experiencia. Revista brasileira de educação. V.11, n.33, set/dez. 2006.

SOUSA, Maria João Ribeiro De. Necessidades das famílias com crianças com autismo, resiliência e suporte social. Dissertação de mestrado em psicologia da educação. Universidade do Algarve, departamento de psicologia e ciências da educação. $\quad$ Faro, 2014. Disponível em: < https://sapientia.ualg.pt/handle/10400.1/8199>. Acesso em: 10 Abr. 2017.

SOUZA, J. R; BARBOZA, R. B. AUTISMO INFANTIL: A IMPORTÂNCIA DO AFETO NA FAMÍLIA. Psicologia em Foco. Faculdade Pio Décimo, Aracaju/SE, v. 6, n. 2, JulDez $2016 . \quad$ Disponível em: $<$ http://periodicos.piodecimo.edu.br/online/index.php/psicologioemfoco/article/view/23 5>. Acesso em: 04 Abr. 2017. 
SOUZA, Aline Cristina De. Famílias de crianças autistas: Compreendendo a participação e os desafios por meio do olhar paterno. Dissertação de mestradouniversidade federal de são Carlos UFSCar, 2016. Disponível em: <https://repositorio.ufscar.br/handle/ufscar/7551>. Acesso em: 04 Abr. 2017.

ZANATTA, Elizangela, et al. Cotidiano de famílias que convivem como autismo infantil. Revista Baiana de Enfermagem, Salvador, v. 28, n. 3, p. 271-282, set./dez. 2014. Disponível em:

https://portalseer.ufba.br/index.php/enfermagem/article/view/10451>. Acesso em: 12 Mar. 2017.

ZANON, R. B; BACKES, B; BOSA, C. A. Identificação dos primeiros sintomas do autismo pelos pais. Psic .: Teor. e Pesq. , Brasília, v. 30, n. 1, p. 25-33, março de 2014. Disponível em: <http://www.scielo.br/scielo.php?script=sci_arttext\&pid=S010237722014000100004\&lng=pt_BR\&nrm=iso >. Acesso em: 05 Abr. 2017.

WALLON, H. Hélène Gratiot-Alfandéry. Tradução e organização por Patrícia Junqueira. Recife: Fundação Joaquim Nabuco, Editora Massangana, 2010.

Enviado: Agosto, 2020.

Aprovado: Setembro, 2020. 